\title{
Topiramate induced metabolic acidosis and kidney stones - a case study
}

\author{
Tomas Salek ${ }^{* 1,2}$, Ivan Andel ${ }^{3}$, Irena Kurfurstova ${ }^{2}$ \\ ${ }^{1}$ Medical Faculty of the University of Ostrava in Ostrava, Ostrava - Zábřeh, Czech Republic \\ ${ }^{2}$ Department of Clinical Biochemistry, Tomas Bata Hospital in Zlín a. s., Zlín, Czech Republic \\ ${ }^{3}$ Department of Urology, Tomas Bata Hospital in Zlín a. s., Zlín, Czech Republic \\ *Corresponding author: tsalek@seznam.cz
}

\begin{abstract}
Introduction: The aim of this study is to present a case of 44 years old woman with topiramate induced metabolic acidosis and kidney stones.

Materials and methods: The laboratory features of topiramate caused renal tubular acidosis in blood and urine during topiramate treatment, with correction of metabolic acidosis by potassium citrate, and after topiramate withdrawal are presented. Differential diagnosis of all possible causes of metabolic acidosis is discussed.

Results: The results revealed negative base excess in extracellular fluid of $-9.2 \mathrm{mmol} / \mathrm{L}$, low serum $\mathrm{HCO}_{3}{ }_{3}$ concentration $(18.6 \mathrm{mmol} / \mathrm{L})$, trend to alkaline urine (pH 6.39) and low urine citrate concentration $(0.3 \mathrm{mmol} / 24 \mathrm{~h})$. After topiramate withdrawal, all parameters of the internal environment normalized.

Conclusions: This study has shown that long-term topiramate administration could induce metabolic acidosis and consequently urholithiasis. Thus, we could recommend testing blood acid base balance, urinary $\mathrm{pH}$ and citrates in patients taking topiramate and suffering from kidney stones.
\end{abstract}

Key words: urolithiasis; acidosis; renal tubular acidosis; topiramate; glomerular filtration rate

\section{Introduction}

Kidney stones affect approximately $10 \%$ of the European population. It means that medical doctors frequently encounter this disease. It is a metabolic disease with urological complications. Kidney stone analysis and identification of risk factors for kidney stone formation are the first steps in the diagnostic procedure in patients with urolithiasis. Risk factors for kidney stone formation include family history of kidney stones, low fluid intake, some types of diets, certain pharmacotherapy, some diseases, increased concentration of stone forming substances and decreased concentration of inhibitors of stone formation. Laboratory medicine plays key role in identification of risk factors. European guidelines on urolithiasis recommend many laboratory blood and urine tests for metabolic evaluation of patients with kidney stones of known and unknown composition. Clear algorithms with treatment decision points are defined for each type of kidney stones for prevention of kidney stone recurrence (1).

The acid base balance plays a very important role mainly in calcium phosphate, uric acid and cystine stone formation. The phosphoric acid system is one of the most important urinary buffers. At the $\mathrm{pH}$ level above the second acid dissociation constant of phosphoric acid (> 6.8) the monohydrogen phosphate $\left(\mathrm{HPO}_{4}{ }^{2-}\right)$ predominates in urine and is able to accept calcium ions. It increases the probability of crystals and stones formation. The systemic metabolic acidosis causes hypercalciuria and hypocitraturia, which also contribute to calcium nephrolithiasis formation. 
Some drugs may also contribute to kidney stones formation. They may crystallize in urine or disturb urine composition. More than 20 drugs which contribute to kidney stone formation are listed in European guidelines (1).

Topiramate is an antiepileptic drug which leads to mixed renal tubular acidosis by the inhibition of carbonic anhydrase in renal tubules, which leads to systemic metabolic acidosis with low plasma bicarbonate concentration and alkaline urine $\mathrm{pH}$ with low urine citrate concentration. These metabolic changes result in calcium phosphate stone formation (2).

The aim of this study is to present a case of a 44 years old woman with topiramate induced metabolic acidosis and kidney stones.

\section{Material and methods}

A 44-year old woman, nonsmoker, presents at urology clinic for right low back pain in April 2012. She did not have signs of renal colic or fever. Her previous medical history included only chronic bronchitis and migraine headaches for years. Since 2007 she was taking topiramate at the daily dose of $200 \mathrm{mg}$ for migraine headache prophylaxis, which greatly improved her headaches. She was also taking sumatriptan in the dose of $50 \mathrm{mg}$ during migraine attack. It was prescribed by pain specialist.

Her body mass index (BMI) was $25.6 \mathrm{~kg} / \mathrm{m}^{2}$. It indicates the range of overweight. Other physical examination did not find any abnormality.

After careful physician examination by urologist in April 2012, plane X-ray of the patient's abdomen was performed, following by computer tomography. She visited urologist regularly every 6 months.

In May 2012, on admission to metabolic clinic arterial blood gas analysis was performed. At the same time blood sample and spot urine sample were obtained in fasting state at 7:00 am. Three weeks later a 24-hour urine sample was obtained. The 24-hour urine specimen was collected in a container with $15 \mathrm{~mL}$ of 6 molar $\mathrm{HCl}$.
In November 2012 morning fasting venous blood sample and spot urine sample was obtained. Fasting venous blood sample and spot urine sample at metabolic clinic were obtained every six months.

VACUETTE $^{\circledR}$ red top $6 \mathrm{~mL}$ tubes (Greiner Bio-One $\mathrm{GmbH}$, Kremsmünster, Austria) with clot activator and without gel separator were used for venous blood collection. The separation of cells from serum was performed within 1 hour. Transport on ice was used for parathormone testing. Capilaries with balanced heparin (Radiometer, Brønshøj, Denmark) were used for arterial blood gas analysis. Transportation of samples was on ice and samples were analyzed within 15 minutes.

Whole blood $\mathrm{pH}$, whole blood $\mathrm{pCO}_{2}$, whole blood $\mathrm{pO}_{2}$ were performed on Radiometer ABL 800 FLEX blood gas analyzer (Radiometer, Brønshøj, Denmark) by electrochemistry methods. Serum glucose, electrolytes, urea, enzymatic creatinine standardized to NIST SRM 967 reference material, uric acid, total bilirubin, alanine aminotransferase, aspartate aminotransferase, gamma-glutamyl transferase, alkaline phosphatase, total cholesterol, triacylglycerols, total protein, albumin, C-reactive protein, serum $\mathrm{HCO}_{3}^{-}$(enzymatic test), cystatin $\mathrm{C}$ traceable to reference material DA ERM 472, parathyroid hormone, urine citrate were measured on ci16200 Abbott Architect analyzer (Abbott Laboratories, Illinois, USA).

Estimation of glomerular filtration rate was calculated by Chronic Kidney Disease Epidemiology Collaboration (CKD-EPI) equation from serum creatinine. $\mathrm{pH}$ in urine was measured on $\mathrm{pH}$ meter PerpHecT Meter 330 (Thermo Scientific, Beverly, USA).

Oxalate in urine is measured on Analytik Jena AG Specord 40 analyzer (Analytik Jena, Jena, Germany). Oxalate is precipitated with calcium sulfate and ethanol, re-dissolved and then oxidized by oxalate oxidase. Reagents are from Instruchemie (Instruchemie, Delfzijl, The Netherlands). Urinary sediment was performed on Arkray analyzer IRIS IQ 200 (Arkray, Kyoto, Japan). Urinary cystin and dibasic aminoacids were mearured on amino acid analyzer AAA 400 (Ingos, Prague, Czech Republic) by 
medium pressure liquid ionex chromatography with postcolumn ninhydrin derivatization and detection at 440 and $570 \mathrm{~nm}$. Polarized light microscopy was used for determination of stone composition.

The patient signed informed consent regarding publication of this article and the case study was approved for publication by the Tomas Bata hospital ethics committee.

\section{Results}

In April 2012, plane X-ray of the abdomen showed presence of the kidney stones. Urolithiasis was confirmed in medium right calyx and inferior left calyx (both in diameter of $3 \mathrm{~mm}$ ) by computed tomography. The composition of the stone was unknown, but the stone was X-ray contrastive. We thought it could be a calcium phosphate stone.
On admission (May 2012), during only topiramate treatment, results of patient arterial blood gas analysis revealed metabolic acidosis (negative base excess of $-9.2 \mathrm{mmol} / \mathrm{L}$ was calculated from $\mathrm{pH}$ and $\mathrm{pCO}_{2}$ ), serum bicarbonate concentration by enzymatic test was $18.6 \mathrm{mmol} / \mathrm{L}$ ), urine analysis showed trend to alkaline urine $(\mathrm{pH}$ 6.39) and low urine citrate concentration $(0.3 \mathrm{mmol} / 24 \mathrm{~h})$ and all other parameters were normal. Results are presented in Table 1. According to results topiramate induced urolithiasis was suspected and patient was advised to discontinue topiramate treatment, but she did not want to as it improves her headaches.

In order to correct metabolic acidosis, since June 2012 potassium citrate was administred to patient. Following therapy, $\mathrm{HCO}_{3}{ }^{-}$concentration was partially corrected to $21 \mathrm{mmol} / \mathrm{L}$. Results are presented in Table 2.

TABLE 1. Results of basic biochemistry analysis, arterial blood gas analysis and urine analysis in patient on admission in May 2012, during topiramate treatment only.

\begin{tabular}{|c|c|c|c|}
\hline Test & Unit & Result & Reference range \\
\hline \multicolumn{4}{|c|}{ Basic biochemistry analysis (9th May 2012) } \\
\hline Serum glucose & $\mathrm{mmol} / \mathrm{L}$ & 6.5 & $3.9-5.5$ \\
\hline Serum sodium & $\mathrm{mmol} / \mathrm{L}$ & 139 & $136-144$ \\
\hline Serum potassium & $\mathrm{mmol} / \mathrm{L}$ & 4.4 & $3.8-5.1$ \\
\hline Serum chloride & $\mathrm{mmol} / \mathrm{L}$ & 111 & $95-107$ \\
\hline Serum urea & $\mathrm{mmol} / \mathrm{L}$ & 4.1 & $2.0-6.7$ \\
\hline Serum creatinine & $\mu \mathrm{mol} / \mathrm{L}$ & 71 & $49-90$ \\
\hline eGFR (CKD-EPI equation) & $\mathrm{mL} / \mathrm{min} / 1.73 \mathrm{~m}^{2}$ & 90 & $90-150$ \\
\hline Serum uric acid & $\mu \mathrm{mol} / \mathrm{L}$ & 219 & $140-340$ \\
\hline Serum total bilirubin & $\mu \mathrm{mol} / \mathrm{L}$ & 6 & $<17$ \\
\hline Serum ALT & $\mathrm{U} / \mathrm{L} 37^{\circ} \mathrm{C}$ & 30.6 & $<43.8$ \\
\hline Serum AST & $\mathrm{U} / \mathrm{L} 37^{\circ} \mathrm{C}$ & 16.2 & $<40.2$ \\
\hline Serum GGT & $\mathrm{U} / \mathrm{L} 37^{\circ} \mathrm{C}$ & 24.6 & $<106.2$ \\
\hline Serum AP & $\mathrm{U} / \mathrm{L} 37^{\circ} \mathrm{C}$ & 51.6 & $<150$ \\
\hline Serum cholesterol & $\mathrm{mmol} / \mathrm{L}$ & 6.45 & $<5$ \\
\hline Serum triacylglycerides & $\mathrm{mmol} / \mathrm{L}$ & 1.71 & $<1.7$ \\
\hline Serum total protein & $g / L$ & 69.4 & $64.0-83.0$ \\
\hline Serum albumin & $g / L$ & 43.9 & $35.0-52.0$ \\
\hline Serum C-reactive protein & $\mathrm{mg} / \mathrm{L}$ & $<1$ & $<3$ \\
\hline Serum $\mathrm{HCO}_{3}^{-}$ & $\mathrm{mmol} / \mathrm{L}$ & 18.6 & $22.0-28.0$ \\
\hline
\end{tabular}


TABLE 1. continued

\begin{tabular}{|c|c|c|c|}
\hline Test & Unit & Result & Reference range \\
\hline Serum calcium & $\mathrm{mmol} / \mathrm{L}$ & 2.25 & $2.10-2.55$ \\
\hline Serum parathyroid hormone & $\mathrm{pmol} / \mathrm{L}$ & 3.6 & $1.6-7.2$ \\
\hline Serum cystatin $C$ & $\mathrm{mg} / \mathrm{L}$ & 0.93 & $0.40-0.96$ \\
\hline \multicolumn{4}{|c|}{ Arterial Blood gas analysis ( $9^{\text {th }}$ May 2012) } \\
\hline Whole blood pH & $\mathrm{pH}$ units & 7.386 & $7.36-7.44$ \\
\hline Whole blood $\mathrm{pCO}_{2}$ & $\mathrm{kPa}$ & 3.61 & $4.6-6.0$ \\
\hline Whole blood $\mathrm{pO}_{2}$ & $\mathrm{kPa}$ & 11.75 & $10.67-14.40$ \\
\hline Actual $\mathrm{HCO}_{3}^{-}$(calculated) & $\mathrm{mmol} / \mathrm{L}$ & 15.9 & $22.0-28.0$ \\
\hline Base excess (calculated) & $\mathrm{mmol} / \mathrm{L}$ & -9.2 & $-2.5-2.5$ \\
\hline Saturation of hemoglobin (measured) & $\%$ & 96.8 & $95.0-99.0$ \\
\hline \multicolumn{4}{|l|}{ Spot urine analysis (9 ${ }^{\text {th }}$ May 2012) } \\
\hline Urine $\mathrm{pH}$ & $\mathrm{pH}$ units & 6.39 & \\
\hline Urine calcium/creatinine & $\mathrm{mol} / \mathrm{mol}$ & 0.38 & $<0.60$ \\
\hline Urine uric acid/creatinine & $\mathrm{mol} / \mathrm{mol}$ & 0.18 & $<0.30$ \\
\hline Urine magnesium/creatinine & $\mathrm{mol} / \mathrm{mol}$ & 0.27 & $0.2-0.5$ \\
\hline Urine oxalate/creatinine & $\mathrm{mol} / \mathrm{mol}$ & 0.011 & $<0.04$ \\
\hline Urine citrate/creatinine & $\mathrm{mol} / \mathrm{mol}$ & 0.03 & $>0.15$ \\
\hline \multicolumn{4}{|l|}{ Urine sediment (9th May 2012) } \\
\hline Erythrocytes in urine sediment & $\times 10^{6} / \mathrm{L}$ & 9 & $<10$ \\
\hline Leukocytes in urine sediment & $x 10^{6} / \mathrm{L}$ & 13 & $<15$ \\
\hline \multicolumn{4}{|c|}{ Biochemistry analysis of $24 \mathrm{~h}$ urine ( $31^{\text {th }}$ May 2012 ) } \\
\hline Urine volume/24h & $\mathrm{L}$ & 2.95 & $1.5-3.0$ \\
\hline Sodium/24h & $\mathrm{mmol} / 24 \mathrm{~h}$ & 145 & $100-260$ \\
\hline Potassium/24h & $\mathrm{mmol} / 24 \mathrm{~h}$ & 71 & $35-80$ \\
\hline Calcium/24h & $\mathrm{mmol} / 24 \mathrm{~h}$ & 6.8 & $2.5-7.5$ \\
\hline Inorganic phosphate/24h & $\mathrm{mmol} / 24 \mathrm{~h}$ & 27 & $13-35$ \\
\hline Magnesium/24h & $\mathrm{mmol} / 24 \mathrm{~h}$ & 3.4 & $3-5$ \\
\hline Oxalate/24h & $\mathrm{mmol} / 24 \mathrm{~h}$ & 0.325 & $0-0.5$ \\
\hline Citrate/24h & $\mathrm{mmol} / 24 \mathrm{~h}$ & 0.3 & $2.5-5.0$ \\
\hline
\end{tabular}

eGFR - estimated glomerular filtration rate; CKD-EPI - Chronic Kidney Disease - Epidemiology Collaboration; ALT - alanine aminotransferase; AST - aspartate aminotransferase; GGT - gamma-glutamyl transferase; AP - alkaline phosphatase.

From May 2013 to July 2014 repeated spot urine samples yielded citrate to creatinine ratio 0.04 , $0.04,0.05$ and 0.05 (reference range is over 0.15 $\mathrm{mol} / \mathrm{mol}$ ). Spot urine $\mathrm{pH}$ ranged from 6.54 to 7.52 .

In December 2014, a regular urologic visit ultrasonography revealed that her stones enlarged. Following these results she stopped taking both topiramate and potassium citrate. After this withdraw- al serum bicarbonate concentration and urine citrates normalized. Results are presented in Table 3. The extracorporeal shock wave lithotripsy was performed on right kidney three times. Urography showed that the patient's calyx neck was narrow but the last lithotripsy, in January 2016, was successful. The stone was composed of calcium phosphate (80\%) and calcium oxalate (20\%). It consist- 
TABLE 2. Results of basic biochemistry analysis and urine analysis in patient in November 2012, during topiramate and potassium citrate treatment

\begin{tabular}{|c|c|c|c|}
\hline Test & Unit & Results & Reference range \\
\hline \multicolumn{4}{|c|}{ Basic biochemistry analysis (14 ${ }^{\text {th }}$ November 2012 ) } \\
\hline Serum sodium & $\mathrm{mmol} / \mathrm{L}$ & 138 & $136-144$ \\
\hline Serum potassium & $\mathrm{mmol} / \mathrm{L}$ & 4.2 & $3.8-5.1$ \\
\hline Serum chloride & $\mathrm{mmol} / \mathrm{L}$ & 110 & $95-107$ \\
\hline Serum $\mathrm{HCO}_{3}^{-}$ & $\mathrm{mmol} / \mathrm{L}$ & 21 & $22.0-28.0$ \\
\hline \multicolumn{4}{|c|}{ Spot urine analysis (14 ${ }^{\text {th }}$ November 2012 ) } \\
\hline Urine $\mathrm{pH}$ & $\mathrm{pH}$ units & 6.79 & \\
\hline Urine calcium/creatinine & $\mathrm{mol} / \mathrm{mol}$ & 0.44 & $<0.60$ \\
\hline Urine citrate/creatinine & $\mathrm{mol} / \mathrm{mol}$ & 0.04 & $>0.15$ \\
\hline
\end{tabular}

TABLE 3. Results of basic biochemistry analysis and urine analysis in patient in December 2014, after both topiramate and potassium citrate withdrawal

\begin{tabular}{llll}
\hline Test & Unit & Results & Reference range \\
\hline Basic biochemistry analysis (10 & & \\
Serum $\mathrm{HCO}_{3}^{-}$ & $\mathrm{mmol} / \mathrm{l}$ & 27 & $22.0-28.0$ \\
Spot urine analysis (15 & & \\
Urine $\mathrm{pH}$ & & & \\
Urine calcium/creatinine & $\mathrm{pH}$ units & 6.28 & $<0.60$ \\
Urine uric acid/creatinine & $\mathrm{mol} / \mathrm{mol}$ & 0.28 & $<0.30$ \\
Urine inorganic phosphate/creatinine & $\mathrm{mol} / \mathrm{mol}$ & 0.28 & $<2.8$ \\
Urine magnesium/creatinine & $\mathrm{mol} / \mathrm{mol}$ & 1.72 & $0.2-0.5$ \\
Urine oxalate/creatinine & $\mathrm{mol} / \mathrm{mol}$ & 0.3 & $<0.04$ \\
Urine citrate/creatinine & $\mathrm{mol} / \mathrm{mol}$ & 0.004 & $>0.15$ \\
\hline
\end{tabular}

ed of Brushite (60\%), Apatite (20\%), and Whedelit (20\%) according to mineralogical terminology.

\section{Discussion}

In the present study we presented a case of the woman with topiramate induced urolithiasis.

Discontinuation of topiramate and normalization of acid base status in our patient confirmed the cause of metabolic acidosis and probably its contribution to kidney stone formation. It was previously described that topiramate can induce systemic metabolic acidosis by multiple mechanisms and lead to calcium phosphate kidney stones, which is consistent with stone composition of our patient. This drug induces renal tubular acidosis. It is combined proximal and distal tubular disorder (3). Low urine citrate excretion, urine $\mathrm{pH}$ over 6 and increased urine $\mathrm{HCO}_{3}^{-}$ion are typical urine profile of topiramate treatment (4).

Her overweight might also have contributed to stone formation, because it is the risk factor for kidney stones formation. It was demonstrated in a study by Shavit et al., that overweight kidney stones formers show clear alterations in metabolic urinary profiles that are associated with increased overall risk of stone formation. This greater risk is primarily due to raised urinary uric acid and sodi- 
um, lower urine $\mathrm{pH}$ and higher prevalence of hypercalciuria (5).

Normalization of metabolic acidosis due to topiramate treatment after its withdrawal was reported in a case study of a 75 year old male (6). It is consistent with our results.

Some cases of metabolic acidosis due to topiramate treatment may be severe with highly negative base excess of - $14.1 \mathrm{mmol} / \mathrm{L}$ (7). We have observed lower degree of metabolic acidosis.

The study by Maalouf et al. showed that the prevalence of symptomatic nephrolithiasis among longterm topiramate users was $10.7 \%$ (8). According to a review of clinical trials provided by Faught et al. of another antiepileptic drug zonisamide (carbonic anhydrase inhibitor), the incidence of clinically symptomatic kidney stones increased with longterm treatment. Among all studies, 15 of 549 patients (2.7\%) had kidney stones (9).

The study by Jhagroo et al. found that urinary citrate excretion declined after starting topiramate therapy. Urinary citrate excretion increased after adding potassium citrate (10). It supports our results.

Kidney stones are the metabolic disease which usually presents as urologic complications mainly as renal colic. The differential diagnosis is broad and includes many internal diseases. The systemic metabolic acidosis can lead to formation of kidney stones. We should consider all potential causes of chronic metabolic acidosis.

Metabolic acidosis may develop during progression of chronic kidney disease (11). The patient had estimated glomerular filtration rate (eGFR) always over $1.0 \mathrm{ml} / \mathrm{s} / 1.73 \mathrm{~m}^{2}$. Patient did not meet the GFR criteria for chronic kidney disease. Urine albumin to creatinine ratio was repeatedly within reference ranges. The patient did not suffer from diabetes mellitus. Her serum glucose concentration did not meet the criterion for diabetes mellitus. Ketoacidosis or biguanide lactic acidosis induced by this disease was not likely. Ethanol induced ketoacidosis was not probable. Very low level of patient's gamma-glutamyl transferase did not indicate alcohol abuse.
She denied chronic diarrhea. Pancreatic and intestinal diseases with diarrhea lead to loss of bicarbonates and metabolic acidosis. Increased absorption of oxalates in malabsorptive states can lead to calcium oxalate stones. Patient had oxaluria within reference ranges.

The combination of metabolic acidosis, low urine citrate and alkaline urine $\mathrm{pH}$ is the typical feature of renal tubular acidosis. Hypocitraturia and trend to alkaline $\mathrm{pH}$ were main features in patient's urine.

Primary hyperparathyroidism causes renal tubular disorder, which is a type of acquired renal tubular acidosis. This endocrine disease is characterized by high serum calcium and parathyroid hormone. It causes metabolic acidosis with formation of calcium oxalate and calcium phosphate stones (12). Elevated chloride concentration is typical for hyperparathyreosis, but normal patient's serum calcium and parathormon level excluded this diagnosis.

The appropriate treatment of patients with calcium kidney stones due to renal tubular acidosis includes alkalization therapy with potassium citrate. The target of treatment is correction of metabolic acidosis with extracellular fluid base excess +/- 2 $\mathrm{mmol} / \mathrm{L}$. Gastrointestinal tolerability of citrates is the clinical issue. The alkali therapy reduces tubular reabsorption of citrates, which increases citrate excretion. If calcium excretion is over $8 \mathrm{mmol} / 24$ hours after restoration of acid base balance, treatment with thiazide is also recommended. General life style changes are also important. Target lifestyle factors include daily fluid intake over 2.5 liters, urine daily volume over 2.5 liters, balanced diet rich in vegetables and fibers, limited $\mathrm{NaCl}$ and animal proteins content in diet, retaining a normal BMI level and adequate physical activity (1).

The study is novel in its detailed description of a complex set of both blood and urine tests during treatment and after it. Possibly the biggest limitation of this study is the fact that it was only performed on a single patient.

We can conclude that we should be aware of topiramate induced metabolic side effects, which include metabolic acidosis and kidney stones. We recommend testing blood acid base balance, uri- 
nary $\mathrm{pH}$ and citrates in patients taking topiramate and suffering from kidney stones.

\section{References}

1. European Association of Urology. Guidelines on Urolithiasis. Available at: http://uroweb.org/guideline/urolithiasis/. Accessed June 10th 2015.

2. Dell'Orto VG, Belotti EA, Goeggel-Simonetti B, Simonetti GD, Ramelli GP, Bianchetti MG, Lava SA. Metabolic disturbances and renal stone promotion on treatment with topiramate: a systematic review. Br J Clin Pharmacol 2014;77:958-64. https://doi.org/10.1111/bcp.12283

3. Mirza N, Marson AG, Pirmohamed M. Effect of topiramate on acid-base balance: extent, mechanism and effects. $\mathrm{Br} \mathrm{J}$ Clin Pharmacol 2009;68:655-61. https://doi.org/10.1111/ j.1365-2125.2009.03521.x

4. Welch BJ, Graybeal D, Moe OW, Maalouf NM, Sakhaee K. (2006) Biochemical and stone-risk profiles with topiramate treatment. Am J Kidney Dis 2006;48:555-63. https://doi. org/10.1053/j.ajkd.2006.07.003

5. Shavit L, Ferraro PM, Johri N, Robertson W, Walsh SB, Moochhala S, Unwin R. Effect of being overweight on urinary metabolic risk factors for kidney stone formation. Nephrol Dial Transplant 2015;30:607-13. https://doi.org/10.1093/ ndt/gfu350

6. Fernández-de Orueta L, Esteban-Fernández J, Aichner HF, Casillas-Villamor A, Rodríguez-Álvarez S. Topiramate-induced metabolic acidosis: a case study. Nefrologia 2012;32:403-4.

\section{Potential conflict of interest}

None declared.

7. Burmeister JE, Pereira RR, Hartke EM, Kreuz M. Topiramate and severe metabolic acidosis: case report. Arqe neuropsiquiatr 2005;63:532-4. https://doi.org/10.1590/S0004282X2005000300032

8. Maalouf NM, Langston JP, Van Ness PC, Moe OW, Sakhaee K. Nephrolithiasis in topiramate users. Urol Res 2011;39:303307. https://doi.org/10.1007/s00240-010-0347-5

9. Faught E. Review of United States and European clinical trials of zonisamide in the treatment of refractory partial-onset seizures. Seizure 2004;13:S59-S65. https://doi. org/10.1016/j.seizure.2004.04.009

10. Jhagroo AR, Wertheim ML,Penniston KL. Alkali replacement raises urinary citrate excretion in patients with topiramateinduced hypocitraturia. Br J Clin Pharmacol 2016;81:131-6. https://doi.org/10.1111/bcp.12751

11. Chen W, Abramowitz MK. Metabolic acidosis and the progression of chronic kidney disease. BMC Nephrol 2014; 15:55. https://doi.org/10.1186/1471-2369-15-55

12. Lila AR, Sarathi V, Jagtap V, Bandgar T, Menon PS, Shah NS. Renal manifestations of primary hyperparathyroidism. Indian J Endocrinol Metab 2012;16:258-62. https://doi. org/10.4103/2230-8210.93745 